\title{
Laparoscopic appendicectomy in a patient with Situs Inversus Totalis
}

\author{
E Keli, KJ Ndri, KH Ahue, OC Blégolé, B Moussa, G Aboua, A Adon, JP Dongui \\ Department of General, Digestive and Endocrine Surgery, Treichville University Hospital, Abidjan, Côte d'Ivoire
}

Corresponding author: E Keli (gbeliekeli@gmail.com)

\begin{abstract}
Summary: We report a case of acute appendicitis in a patient with Situs Inversus Totalis (SIT) successfully managed by laparoscopic surgery to highlight awareness of this rare condition and the diagnostic difficulties and technical considerations posed by this anatomical anomaly when conducting surgery.
\end{abstract}

S Afr J Surg 2019;57(2)

http://dx.doi.org/10.17159/2078-5151/2019/v57n2a2951

\section{Case presentation}

A 34-year-old male presented to the surgical emergency department with a 12-hour history of acute onset abdominal pain. The diagnosis of SIT was established at the age of 13 years on a chest radiograph which showed dextrocardia and was confirmed 10 years later during a health check.

On examination the patient was apyrexial and normotensive with a pulse of $80 /$ minute. He had left lower quadrant pain with tenderness. Laboratory tests showed a mild leucocytosis (white cell count $11.5 \times 10 \mathrm{E} 9 / \mathrm{L}$ and a C-reactive protein of $48 \mathrm{mg} / \mathrm{L}$. An abdominal ultrasound showed atonic intestinal loops with free peritoneal fluid in the left lower quadrant and demonstrated a left-sided appendix and liver and rightsided spleen. A chest X-ray and computed tomography (CT) confirmed dextrocardia (Figures 1a and b).

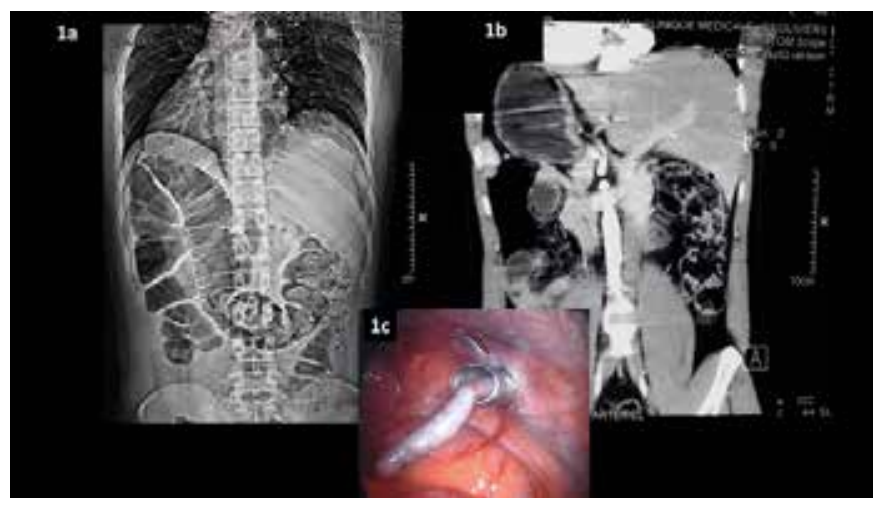

Figure 1a: Standard radiograph showing transposition of thoracic and abdominal viscera

Figure 1b: CT-scan image of situs inversus showing liver in the left side

Figure 1c: Removal of inflamed appendix
A laparoscopic appendicectomy was performed with the patient in the supine position under general anaesthesia. The camera was inserted through a sub-umbilical $10 \mathrm{~mm}$ port that was placed using an open technique. An additional $10 \mathrm{~mm}$ trocar with a reducer was placed in the right lower quadrant and a $5 \mathrm{~mm}$ trocar into the right lower quadrant. Inspection of the peritoneal cavity confirmed the features of SIT and an inflamed left-sided appendix. The mesoappendix was isolated and divided using coagulation and the appendicectomy completed and the specimen removed through the right lower quadrant port (Figure 1c).

The postoperative course was uneventful and the patient discharged on the second postoperative day. Pathological examination of the excised appendix confirmed the diagnosis of acute appendicitis.

\section{Discussion}

True left-sided acute appendicitis (LSAA) develops in association with two types of congenital anomalies, namely SIT and midgut malrotation (MM). Situs inversus (SI) is a rare autosomal recessive congenital positional anomaly characterised by the transposition of the abdominal viscera which may be associated with dextrocardia known as situs inversus totalis (SIT).

SIT results in a mirror rotation of the abdominal internal viscera and transposition of the thoracic organs and occurs with an incidence in the population of only $0.001 \%$ with a male-to-female ratio of $3: 2 .{ }^{1}$ LSAA in the absence of SIT or MM may present as an atypical presentation of right-sided, but long appendix, which projects into the left lower quadrant. Until 2008, fewer than 10 cases of true LSAA associated with SIT were reported in the literature. ${ }^{2}$

After establishing the diagnosis of SIT, the surgical 
options are the same as for normal patients. Laparoscopic appendectomy in SIT was first performed in 1998 by Contini et al. in a 34-year-old male patient. ${ }^{3}$ In a recent review of 95 cases of LSAA of whom 66 had SIT, laparoscopic appendicectomy was attempted in eight cases. ${ }^{4}$ In two of the eight cases there was conversion to an open procedure. Since then, laparoscopic appendicectomy has been performed in a total of 20 cases ( 12 with MM and 8 with SIT). ${ }^{4}$ Laparoscopy is useful both in establishing the diagnosis and in performing the definitive surgery, particularly so, as is the case with rightsided appendicitis, in females. ${ }^{5}$ The technique used in our case was conventional with three ports. However, single-incision multi-port appendicectomy for a patient with SIT has been reported. ${ }^{6}$

Imaging is helpful in the diagnosis of LSAA as well as confirming SIT or MM. A plain abdominal radiograph or chest $\mathrm{x}$-ray may show dextrocardia or a left-sided liver. Abdominal ultrasound can be useful in locating the position of the inflamed appendix. Cross-sectional imaging (CT or MRI) is superior in showing the extent of malrotation or completeness of situs inversus.

\section{Conclusion}

LLAA is rare and is generally associated with SIT and MM. Imaging and laparoscopy are helpful in resolving diagnostic difficulties associated with the conditions. These investigations allow the early intervention of LSAA and guide port placements during laparoscopic appendicectomy.

\section{REFERENCES}

1. Golash V. Laparoscopic management of acute appendicitis in situs inversus. J Minim Access Surg. 2006;2(4):220-1.

2. Huang SM, Yao CC, Tsai TP, Hsu GW. Acute appendicitis in situs inversus totalis. J Am Coll Surg. 2008;207(6):954.

3. Contini S, Dalla Valle R, Zinicola R. Suspected appendicitis in situs inversus totalis: an indication for a laparoscopic approach. Surg Laparosc Endosc. 1998;8(5):393-4.

4. Akbulut S, Ulku A, Senol A, Tas M, Yagmur Y. Left-sided appendicitis: review of 95 published cases and a case report. World J Gastroenterol. 2010;16(44):5598-602.

5. Song JY, Rana N, Rotman CA. Laparoscopic appendectomy in a female patient with situs inversus: case report and literature review. JSLS. 2004;8(2):175-7.

6. Rajkumar JS, Syed A, Anirudh JR, Kishor CM, Ganesh D. Single-Incision Multi-Port Appendectomy for a Patient with Situs Inversus Totalis: First case report. Sultan Qaboos Univ Med J. 2016;16(2):e242-5. 